\title{
Conventional mesh repair of a giant iatrogenic bilateral diaphragmatic hernia with an enterothorax
}

This article was published in the following Dove Press journal:

International Medical Case Reports Journal

12 February 2014

Number of times this article has been viewed

\author{
Philipp Lingohr' \\ Thomas Galetin ${ }^{2}$ \\ Boris Vestweber ${ }^{2}$ \\ Hanno Matthaei' \\ Jörg C Kalff' \\ Karl-Heinz Vestweber ${ }^{2}$ \\ 'Department of Surgery, University of \\ Bonn, Bonn, Germany; ${ }^{2}$ Department \\ of Surgery, Klinikum Leverkusen, \\ Leverkusen, Germany
}

\begin{abstract}
Purpose: Diaphragmatic hernias (DHs) are divided into congenital and acquired hernias, most of which are congenital. Among acquired DHs, up to $80 \%$ are left-sided, only a few iatrogenic DHs have been reported, and bilateral hernias are extremely rare. For diagnostic reasons, many DHs are overlooked by ultrasonography or X-ray and are only recognized at a later stage when complications occur.
\end{abstract}

Methods: In 2009, we performed three partial diaphragm replacements in our clinic for repairing DHs using a PERMACOL ${ }^{\mathrm{TM}}$ implant.

Results: As all patients had uneventful postoperative courses and the clinical outcomes were very good, we present one special case of a 65 -year-old male with a giant iatrogenic bilateral DH with an enterothorax.

Conclusion: We see a good indication for diaphragm replacements by using a PERMACOL ${ }^{\text {TM }}$ implant for fixing especially DHs with huge hernial gaps and in cases with fragile tissue.

Keywords: bilateral diaphragmatic hernia, enterothorax, conventional hernia repair, PERMACOL ${ }^{\mathrm{TM}}$, biological implant, diaphragm replacement, mesh repair

\section{Introduction}

Non-traumatic diaphragmatic hernias (DHs) are mainly of congenital origin, whereas DHs in adults are seen in blunt $(0.8 \%-5 \%$ incidence) or penetrating $(10 \%-15 \%$ incidence) thoracoabdominal trauma. ${ }^{1-3}$ Among acquired DHs, up to $80 \%$ are leftsided, bilateral hernias are extremely rare, and only a few iatrogenic DHs have been reported. ${ }^{4}$ Most acquired DHs are caused by sternotomies in adult and pediatric cardiac surgery and abdominal surgery. ${ }^{5-10}$

The majority of traumatic or iatrogenic DHs manifest immediately or shortly after an accident. Despite there being various diagnostic tools, some hernias can still be overlooked and only recognized at a later stage when complications resulting from the herniated organs have manifested..$^{2,11-14}$ Nevertheless, some develop long after the injury and only turn symptomatic after an interval of months or years. ${ }^{15,16}$ The main symptoms of DHs are abdominal/chest pain and dyspnea due to pulmonary compression, bowel obstruction and strangulation, which were present in our case.

Thoracotomy and/or laparotomy are often required in a hemodynamic unstable polytraumatic patient. However, thoracoscopy and/or laparoscopy have recently been suggested in the literature to be helpful for both the diagnosis and treatment of these lesions in order to reduce the high morbidity and mortality rates seen with open procedures. ${ }^{2,13,17-20}$ Although the closure technique for the hernia site is still a matter of discussion, direct closure without plastic seems to be favored by some authors. ${ }^{13,18}$
Correspondence: Philipp Lingohr Department of Surgery, University of Bonn, Sigmund-Freud-Strasse 25, $53 \mid 27$ Bonn, Germany

$\mathrm{Tel}+49228287 \quad 15215$

Fax +49228287 19585

Email philipp.lingohr@ukb.uni-bonn.de 


\section{Case report}

The reported patient is a 65 -year-old male. During a vocal cord operation 10 years before, there was an accidental intralaryngeal gas explosion that required several subsequent tracheal reconstructions. Consequently, a huge bilateral diaphragmatic hernia developed over the years.

As the patient was suffering from progredient dyspnea, a computed tomography was performed, which showed a complete enterothorax (Figure 1); therefore, an operative approach was indicated. The upper abdomen was incised by transverse laparotomy revealing a large package of small intestine ventrally disappearing on both sides of the chest (Figure 2). The adhesions were divided and the parts of the colon and jejunum that were dislocated in the chest were repositioned into the abdomen. Some parts were partially strangulated but still in good shape. The stomach, however, was in the correct anatomical location. After repositioning and resection of the hernial sac, the hernial gap could hardly be adapted (Figure 3 ). The diaphragm was very weak, which suggested that a direct closure would be too fragile. For this reason, a large flap of PERMACOL ${ }^{\text {TM }}$ (original size: $18 \mathrm{~cm} \times 28 \mathrm{~cm} \times 1.5 \mathrm{~cm}$; Covidien Ltd, Dublin, Ireland) was trimmed to fit so that it covered both sides of the dorsal diaphragm and the ventral part of the flap overlapped with the abdominal wall incision (Figure 4). The flap was fixed all around with VICRYL ${ }^{\text {TM }} 0$ sutures (Johnson \& Johnson, New Brunswick, NJ, USA; Figure 5). As a pneumothorax on the right

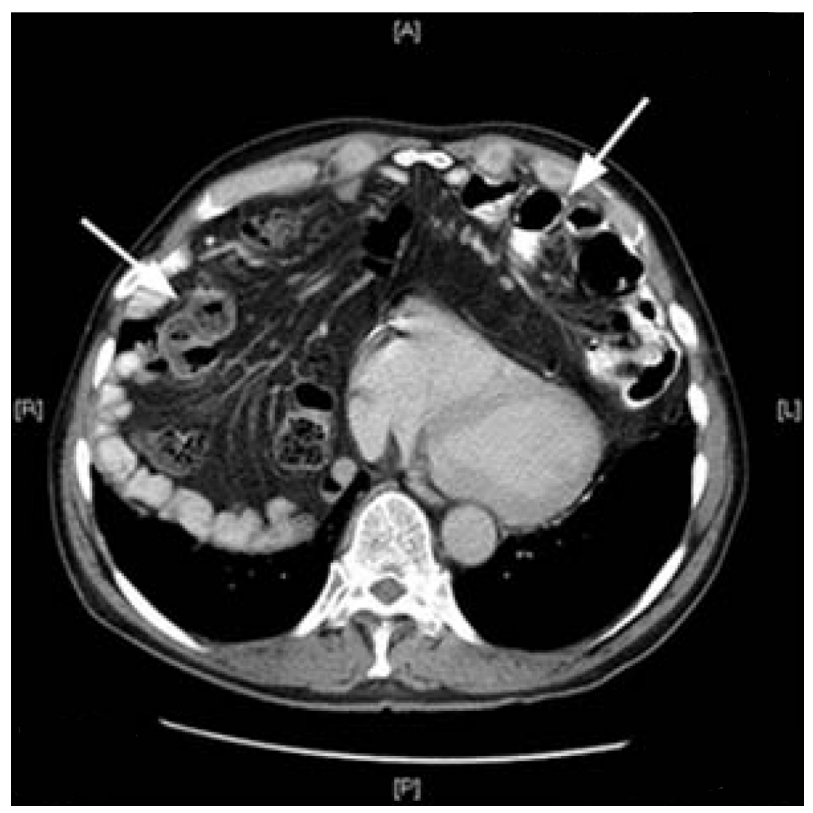

Figure I Computed tomography scan of the thorax showing a complete enterothorax (arrows).

Abbreviations: A, anterior; L, left; $P$, posterior; $R$, right.

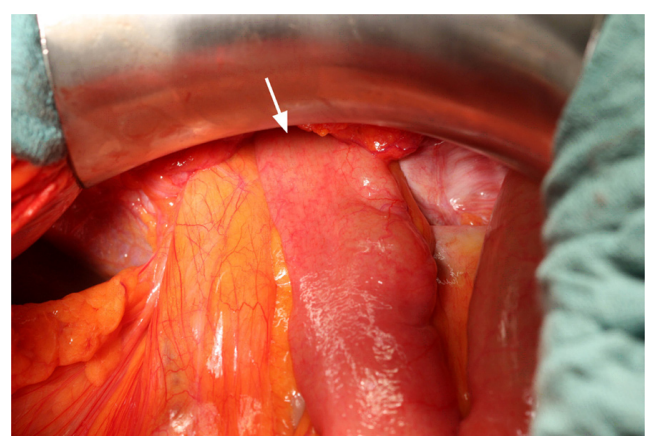

Figure $2 \mathrm{~A}$ large package of small intestine disappearing on both sides of the chest.

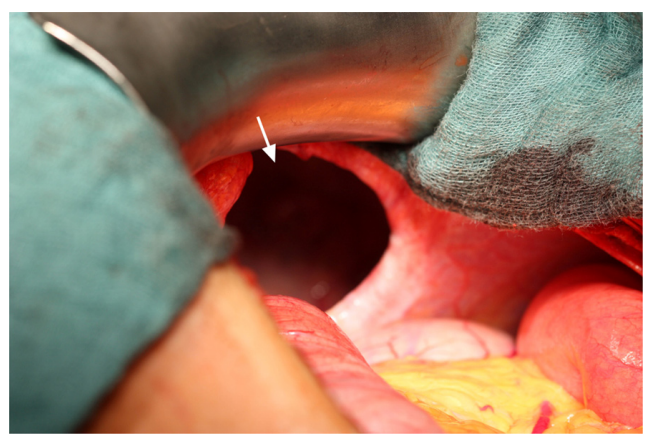

Figure 3 Huge hernial gap in the diaphragm.

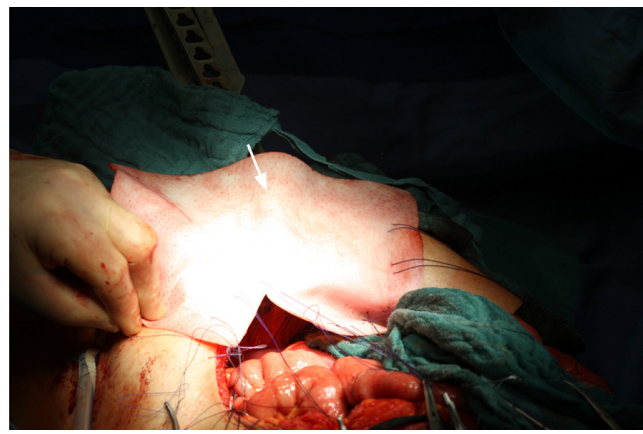

Figure 4 Cutting and fitting of the PERMACOL ${ }^{\mathrm{TM}}$ implant. Note: PERMACOL ${ }^{\mathrm{TM}}$ is manufactured by Covidien Ltd, Dublin, Ireland.

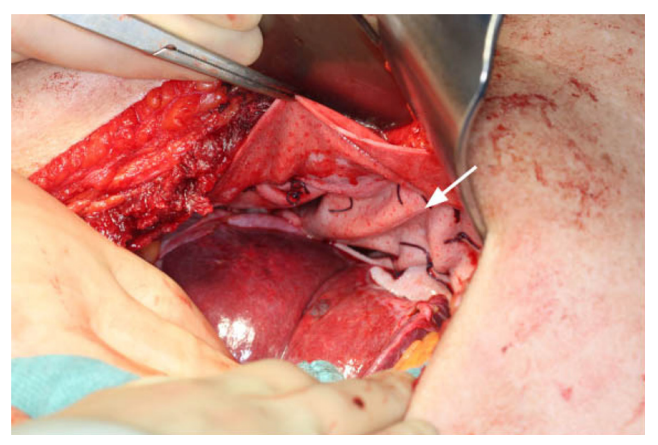

Figure 5 Final result after fixing the PERMACOL ${ }^{T M}$ implant with VICRYL ${ }^{T M}$ sutures. Notes: PERMACOL ${ }^{\mathrm{TM}}$ is manufactured by Covidien Ltd, Dublin, Ireland. VICRYL ${ }^{\mathrm{TM}}$ is manufactured by Johnson \& Johnson, New Brunswick, NJ, USA. 
side was provoked by the manipulation, thoracic drainage was applied. The abdominal wall was occluded involving the ventral edge of the PERMACOL ${ }^{\mathrm{TM}}$ flap to provide for more stability.

The postoperative course was uneventful apart from paroxysmal atrial fibrillation and the patient was released from hospital 16 days after operation.

The postoperative follow-up after 3 and 6 months including a computed tomography scan did not reveal any pathologies.

\section{Discussion}

The interesting aspects of this case are the huge bilateral expansion of the DH and the unusual iatrogenic cause preceding the symptoms by 10 years.

The distinct weakness of the entire diaphragm - a hint of the chronic progress of the hernia - required reconstruction by an implant. Usually, synthetic mesh like polytetrafluoroethylene is used to close hernial gaps but also other material is sometimes used. In this case, we decided to use a large porcine dermal collagen flap which serves as a matrix for cell ingrowth and neovascularization, because of its very good biocompatibility. Even though there was a previous report about the rejection of a PERMACOL ${ }^{\mathrm{TM}}$ implant used in abdominal wall repair, in our case, we had no postoperative complications or any hernia relapse..$^{21}$

\section{Conclusion}

Based on our experience, PERMACOL ${ }^{\mathrm{TM}}$ implants are a good choice for diaphragm replacements especially for fixing DHs with huge hernial gaps and in cases with fragile tissue.

Finally, prospective and randomized trials have to be performed to resolve the pros and cons of this procedure.

\section{Disclosure}

The authors report no conflicts of interest in this work.

\section{References}

1. Ghanem AN, Chankun TS, Brooks PL. Total gastric gangrene complicating adult Bochdalek hernia. Br J Surg. 1987;74(9):779.
2. Nau T, Seitz H, Mousavi M, Vecsei V. The diagnostic dilemma of traumatic rupture of the diaphragm. Surg Endosc. 2001;15(9):992-996.

3. Rossetti G, Brusciano L, Maffettone V, et al. Giant right post-traumatic diaphragmatic hernia: laparoscopic repair without a mesh. Chir Ital. 2005;57(2):243-246.

4. Sirbu H, Busch T, Spillner J, Schachtrupp A, Autschbach R. Late bilateral diaphragmatic rupture: challenging diagnostic and surgical repair. Hernia. 2005;9(1):90-92.

5. Ashour K, Jamieson K, Lakhoo K. A sternotomy too far. Interact Cardiovasc Thorac Surg. 2009;9(4):753-754.

6. Bettolli M, Jackson CC, Sweeney B, Rubin S. Iatrogenic anterior diaphragmatic hernia in childhood. Eur J Pediatr Surg. 2008;18(4): 275-276.

7. Chin RY, Glew MJ, Brady P. Iatrogenic intrapericardial diaphragmatic hernia. ANZ J Surg. 2002;72(9):681-683.

8. Drafts BC, Chughtai HL, Entrikin DW. Iatrogenic intrapericardial diaphragmatic hernia diagnosed by cardiovascular magnetic resonance. J Cardiovasc Magn Reson. 2010;12:3.

9. Dukhno O, Peiser J, Levy I, Ovnat A. Iatrogenic diaphragmatic hernia due to laparoscopic gastric banding. Surg Obes Relat Dis. 2006;2(1): $61-63$.

10. Muysoms FE, Cathenis KK, Hamerlijnck RP, Claeys DA. Laparoscopic repair of iatrogenic diaphragmatic hernias after sternectomy and pedicled omentoplasty. Hernia. 2009;13(6):617-623.

11. Cristofaro MG, Lazzaro F, Cafaro D, et al. [Post-traumatic diaphragmatic hernia with late diagnosis. Report of a clinical case]. Ann Ital Chir. 2000;71(5):595-598. Italian.

12. Montresor E, Procacci C, Guarise A, et al. Strangulated traumatic hernia of the diaphragm. A report of two cases. Chir Ital. 1999;51(6): 471-476.

13. Ruf G, Mappes HJ, Kohlberger E, Baumgartner U, Farthmann EH. [Diagnosis and therapy of diaphragmatic rupture after blunt thoracic and abdominal trauma]. Zentralbl Chir. 1996;121(1):24-29. German.

14. Scaglione M, Pinto F, Grassi R, et al. [Diagnostic sensitivity of computerized tomography in closed trauma of the diaphragm. Retrospective study of 35 consecutive cases]. Radiol Med. 2000;99(1-2):46-50. Italian.

15. Alimoglu O, Eryilmaz R, Sahin M, Ozsoy MS. Delayed traumatic diaphragmatic hernias presenting with strangulation. Hernia. 2004;8(4): 393-396.

16. Carter BN, Giuseffi J, Felson B. Traumatic diaphragmatic hernia. Am J Roentgenol Radium Ther. 1951;65(1):56-72.

17. Koehler RH, Smith RS. Thoracoscopic repair of missed diaphragmatic injury in penetrating trauma: case report. J Trauma. 1994;36(3): 424-427.

18. Kurata K, Kubota K, Oosawa H, Eda N, Ishihara T. Thoracoscopic repair of traumatic diaphragmatic rupture. A case report. Surg Endosc. 1996;10(8):850-851.

19. Meyer G, Hüttl TP, Hatz RA, Schildberg FW. Laparoscopic repair of traumatic diaphragmatic hernias. Surg Endosc. 2000;14(11):1010-1014.

20. Wadhwa A, Surendra JB, Sharma A, et al. Laparoscopic repair of diaphragmatic hernias: experience of six cases. Asian J Surg. 2005;28(2): $145-150$.

21. Wotton FT, Akoh JA. Rejection of Permacol mesh used in abdominal wall repair: a case report. World J Gastroenterol. 2009;15(34):4331-4333.
International Medical Case Reports Journal

\section{Publish your work in this journal}

The International Medical Case Reports Journal is an international, peer-reviewed open-access journal publishing original case reports from all medical specialties. Previously unpublished medical posters are also accepted relating to any area of clinical or preclinical science. Submissions should not normally exceed 2,000 words or

\section{Dovepress}

4 published pages including figures, diagrams and references. The manuscript management system is completely online and includes a very quick and fair peer-review system, which is all easy to use. Visit http://www.dovepress.com/testimonials.php to read real quotes from published authors. 